\title{
Incidence and Risk Factors Associated with Technique Failure in the First Year of Peritoneal Dialysis: A Single Center Retrospective Cohort Study in Southern China
}

\section{Xiao Yang ( $\nabla$ yxiao@mail.sysu.edu.cn )}

First Affiliated Hospital of Sun Yat-sen University

\section{Xiao Dong}

Sun Yat-sen University

\section{Haishan Wu}

First Affiliated Hospital of Sun Yat-sen University Hongjian Ye

First Affiliated Hospital of Sun Yat-sen University

Chunyan Yi

First Affiliated Hospital of Sun Yat-sen University

\section{Xiangwen Diao}

First Affiliated Hospital of Sun Yat-sen University

Ruihua Liu

First Affiliated Hospital of Sun Yat-sen University

\section{Haiping Mao}

First Affiliated Hospital of Sun Yat-sen University

\section{Fengxian Huang}

First Affiliated Hospital of Sun Yat-sen University

\section{Xueqing Yu}

Guangdong Provincial People's Hospital

\section{Research Article}

Keywords: Technique failure, Peritoneal dialysis, Transferring to hemodialysis, Death

Posted Date: January 18th, 2022

DOI: https://doi.org/10.21203/rs.3.rs-1148030/v1

License: (1) (i) This work is licensed under a Creative Commons Attribution 4.0 International License. Read Full License 
Page $2 / 20$ 


\section{Abstract}

Background: Technique failure is more likely to occur during the first 12 months after peritoneal dialysis (PD) initiation, which is a great challenge encountered in PD patients. The aim of this study was to investigate the incidence and risk factors associated with technique failure within the first year of PD patients in Southern China.

Methods: Incident PD patients who were followed up for at least one year at The First Affiliated Hospital of Sun Yat-sen University from January 1, 2006 to December 31, 2015 were included. Technique failure was defined as transfer to hemodialysis (HD) for more than 30 days or death within the first year after start of PD. A competitive risk regression analysis was used to explore the incidence and risk factors of the technique failure.

Results: Overall, 2,290 incident PD patients were included in this study, with a mean age of $48.2 \pm 15.7$ years, $40.9 \%$ female and $25.2 \%$ with diabetes. A total of 173 patients $(7.5 \%)$ had technique failure during the first year of PD. Among them, the patient death account for $62.4 \%(n=108)$ and transferring to HD account for $37.6 \%(n=65)$. The main reasons for death were cardiovascular diseases $(n=32,29.6 \%)$, infection ( $n=15,13.8 \%)$ and for conversion to HD were catheter dysfunction $(n=28,16.2 \%)$, infection $(n=22,12.7 \%)$. The risk factors for the technique failure included advanced age (HR 2.78, 95\% Cl 1.824.30), low body mass index (BMI $18.5 \mathrm{~kg} / \mathrm{m}^{2}$ : HR 1.77, 95\% $\mathrm{Cl} 1.17-2.67$ ), history of congestive heart failure (HR 2.81, 95\% Cl 1.58-4.98), or HD (HR 1.49, 95\% Cl 1.05-2.10), peritonitis (HR 2.02, 95\% Cl 1.36$3.01)$; while higher serum albumin ( $\mathrm{HR} 0.93,95 \% \mathrm{Cl} 0.89-0.96)$ and using employee medical insurance to pay expenses (HR $0.47,95 \% \mathrm{Cl} 0.32-0.69)$ were associated with reduced risk.

Conclusions: Advanced age, poor nutritional status, history of HD or congestive heart failure, and peritonitis are related factors that increase the risk of technique failure in first year of PD, while patients' type of medical insurance may also have an influence on early technique failure.

\section{Introduction}

The first year after the initiation of peritoneal dialysis (PD) is considered to be a high-risk period for PD failure. Studies have shown that about $40 \%$ of technique failures occurred in the first year of PD[1], which is a great challenge encountered in PD patients and a barrier to increased uptake of PD. The technique failure was defined as either transfer to hemodialysis (HD) for $\geq 30$ days (death-censored) [2] or including death[3]. Due to the differences in the definition of technique failure, the technique failure rates during the first year of PD reported in different studies were varied from 12-26\%[4].The high technique failure rate in the early stage of PD directly offset the advantages of PD over HD in terms of economy and quality of life.

Australian and New Zealand Dialysis and Transplant Registry Centre (ANZDATA) showed that mechanical and other causes account for more cases during the first nine months of PD treatment[3]. A study on patients from the French Language Peritoneal Dialysis Registry (RDPLF) showed that patients treated by 
HD before PD and failed transplant patients had a higher risk of early PD failure when competing events were considered[5]. However, the key risk factors of technique failure within first year of PD treatment are still unclear. In the current study, we conducted a single center retrospective cohort study in Southern China to determine the incidence and risk factors associated with the technique failure within the first year of PD patients.

\section{Methods}

\section{Design and population}

This study was a single center retrospective cohort study. All adult patients (over 18 years old) who were catheterized and followed up for at least one year at The First Affiliated Hospital of Sun Yat-sen University from January 1, 2006 to December 31, 2015 were included. The study was conducted in compliance with the ethical principles of the Helsinki Declaration and approved by the Human Ethics Committees of Sun Yat-sen University. All participants were asked for permission to use their medical data for noncommercial studies, and written informed consent was obtained at the initiation of PD.

\section{Study definitions}

The technique failure was defined as transfer to HD for $\geq 30$ days or death [3]. Peritonitis was diagnosed when at least 2 of the following were present: abdominal pain and/or cloudiness of dialysis effluent; white blood cell count in dialysis effluent $>100 / \mu \mathrm{L}$, with $>50 \%$ polymorphonuclear leukocytes; and a positive culture from dialysis effluent [6]. Cardiovascular disease (CVD) was defined as a history of congestive heart failure, angina, myocardial infarction, coronary heart disease, cerebrovascular event, or peripheral vascular disease[7]. Cardiovascular (CV) death was defined as death due to congestive heart failure, acute myocardial infarction, cardiac arrhythmia, sudden cardiac arrest, cerebrovascular accident or peripheral vascular disease[8].

\section{Data collection}

Prior to PD initiation, serum creatinine (Scr) was collected and baseline estimated glomerular filtration rate (eGFR) was calculated using the Modification of Diet in Renal Disease (MDRD) equation[9]. Other baseline data during the first 1-3 months of PD initiation were also collected, including demographic (age, gender, primary cause of end stage renal disease (ESRD), presence of diabetes, history of CVD, education levels (Higher education is defined as the completion of 12 years of compulsory education or above), Medical insurance (The type of health insurance depends on the type of health insurance card that the patient pays for). complications, duration of RRT, self-care ability (defined as whether the self-changing tube can be completed or not), occurrence of first peritonitis and body mass index (BMI)). Biochemical data including levels of hemoglobin, serum albumin, creatinine, immunoreactive parathyroid hormone, albumin-corrected calcium, phosphorus, triglycerides, total cholesterol, high-density lipoprotein cholesterol (HDL-C) and low-density lipoprotein cholesterol (LDL-C).

\section{Clinical outcomes}


The primary outcome was technique failure within the first year of PD initiation[2]. Secondary outcomes were cause-specific early technique failure including transfer to HD and death.

\section{Statistical analysis}

Categorical variables were expressed as frequency and proportion. Mean and standard deviation (SDS) were used to summarize normally distributed continuous variables. Median and interquartile range (IQR) were used to summarize continuous variables not following a normal distribution. $\chi 2$ test was used to compare the classified variables between groups, and Mann-Whitney test was used to test the skewed continuous variables. The risk factors of early technique failure were statistically analyzed by multivariate competitive risk regression model and renal transplantation was regarded as a competitive risk factor. The multivariate model included the related variables based on univariate analysis $(P<0.05)$. The interaction terms between covariables were tested in advance. Competitive risk regression analysis was also used to test secondary outcomes, and technique failures caused by death and transfer to HD were analyzed separately as target results. In these analyses, competing risks were transplant and the cause of other technique failures (death, transfer to HD). All covariates in the final model for the primary outcome were included in models for the secondary outcomes. In addition, we also generated a cumulative correlation function curve for each specific cause of technique failure (death, mechanical, infection, etc.) The data were analyzed by Stata/SE16.0, P < 0.05 was considered statistically significant.

\section{Results}

\section{Study population and baseline characteristics}

A total of 2,317 incident PD patients were follow-up at our PD center, of them 28 patients with age younger than 18 years were not included. The remaining 2,290 patients were enrolled in this study (Figure 1). The mean age was $48.2 \pm 15.7$ years, $59.1 \%$ were male and $25.2 \%$ with diabetes. Baseline characteristics are described in Table 1. During the first year of PD, 108(4.7\%) had died, 65(2.8\%) patients had transferred to HD, 169(7.3\%) cases had received kidney transplantation, and 57(2.4\%) cases had been lost to follow-up. The technique failure rate within the first year of PD (including death and transferring to HD) was $7.5 \%$ ( $\mathrm{n}=173$ patients).

\section{The causes of technique failure in the first year of PD}

Among the 173 cases of technique failure occurred in the first year of PD, death account for $62.4 \%$ $(n=108)$ and transferring to HD account for $37.6 \%(n=65)$. The main reasons for death were cardiovascular diseases $(n=32,29.6 \%)$, infectious diseases $(15,13.8 \%)$ and for transferring to HD were catheter dysfunction $(n=28,16.2 \%)$, infection $(n=22,12.7 \%)$, and other causes $(n=15,8 \%)$ (Figure 1, Table 1). The risk of technique failure caused by death was constant and obvious during the first year of PD. In the first six months, the incidence of technical failures caused by mechanical problems was much higher 


\section{The risk factors associated with the technique failure during the first year of PD}

The related variables in the multivariate model were based on univariate analysis $(P<0.05)$, which included age, gender, BMI, primary disease, laboratory data, education level, complications, duration of RRT, self-care ability, occurrence of first peritonitis. The results shown that advanced age (HR $2.78,95 \% \mathrm{Cl}$ 1.82-4.30), low body mass index (BMI $18.5 \mathrm{~kg} / \mathrm{m}^{2}$ : HR 1.77, 95\% $\mathrm{Cl} 1.17-2.67$ ), congestive heart failure (HR 2.81, 95\% Cl 1.58-4.98), time on HD before PD $\leq 3$ months (HR $1.4995 \% \mathrm{Cl} 1.05-2.10$ ), peritonitis (HR $2.02,95 \% \mathrm{Cl} 1.36-3.01)$; while higher serum albumin ( $\mathrm{HR} 0.93,95 \% \mathrm{Cl} 0.89-0.96)$ and using employee medical insurance to pay medical expenses $(\mathrm{HR} 0.47,95 \% \mathrm{Cl} 0.32-0.69)$ were associated with reduced risk. (Table 2).

\section{The risk factors associated with the technique failure caused by death or by transferring to HD}

In the multivariate analysis for the event of interest, advanced age ( $\geq 65$ years old: $\mathrm{HR} 4.36,95 \% \mathrm{Cl} 2.46$ 7.74), too low BMI (BMI $<18.5 \mathrm{~kg} / \mathrm{m}^{2}$ : HR $2.42,95 \% \mathrm{Cl} 1.44-4.06$ ) and time on HD before PD $\leq 3$ months (HR 1.68, 95\% Cl 1.05-2.69), congestive heart failure (HR 3.52, 95\% Cl 1.83-6.75), were associated with an increased risk of death. Complete self-care ability ( $\mathrm{HR} 0.53,95 \% \mathrm{Cl} 0.32-0.88)$, using employee medical insurance to pay medical expenses (HR $0.41,95 \% \mathrm{Cl} 0.24-0.70$ ), and higher serum albumin (HR 0.92, $95 \% \mathrm{Cl}$ 0.88-0.96) were associated with a decreased risk of death in the first year of PD (Table 2).

PD-related peritonitis (HR 3.95, 95\% Cl 2.25-6.80) was associated with the increased risk, while using employee medical insurance to pay medical expenses (HR 0.55, 95\% Cl 0.31-0.99) was associated with reduced risk for the technique failure in the first year of PD caused by transferring to HD (Table 2).

\section{Discussion}

In this retrospective cohort study, we analyzed the incidence and risk factors of the technique failure in the first year of PD on 2,290 incident PD patients. Overall, the incidence of technique failure within the first year after the start of PD was $7.5 \%$. The rate of technique failure due to death was $4.7 \%$ and due to transferring to HD was $2.8 \%$. The main causes of early death were cardiovascular diseases and infectious diseases, while the main causes of early transfer to HD were mechanical failure and infection. Advanced age, lower BMI, history of HD or congestive heart failure and peritonitis, were the factors associated with increased risk, while using employee medical insurance to pay expenses and high serum albumin associated with decreased risk for the technique failure. 
In a study involving more than 30,000 patients in the United States, the rate of transferring to HD during 1 year reached $18.7 \%-20.5 \%$ [10]. ANZDATA Study on 16,748 PD patients reported that 4,389 patients $(26.2 \%)$ developed early technique failure (including death and transferring to HD) during the first year of PD therapy. In a study of Singapore, $19 \%$ of patients developed to technique failure (including death and transferring to HD) in first year after PD start[11]. A retrospective cohort study of 5,162 PD patients in Canadian showed that the 1-year conversion rate to HD was 12.7\%[12]. In current study, the technique failure rate within the first year of PD in our center was 7.5\%. The relative low incidence of technique failure in the early stage of PD may attribute to the Asian race, younger cohort, less comorbidity and larger PD center size[13, 14]. More than 1,000 PD patients have been followed up by a well-trained PD team in our center since 2012. A unique therapy and management approach that includes a standardized procedure for catheter insertion, a carefully designed PD prescription, a meticulous and comprehensive patient training and follow-up care may involve in the lower technique failure rate [15].

We found that death was the leading cause of the technique failure. Among the 173 cases of technique failure occurred in the first year of PD, death account for $62.4 \%$. In a Dutch study, deaths accounted for $69 \%$ of the total number of early technique failures[16]. Studies in South Korea, Singapore and Canada also demonstrated that death was the leading cause of early withdrawal from PD[11, 12, 17]. In our study, cardiovascular (CV) death was the leading cause of death (29.6\%). We found that a baseline history of congestive heart failure was also a risk factor for death and technique failure. According to recent reports, patients with volume overload at the baseline have a higher risk of death and conversion to HD over the next 12 months[18]. The early history of heart failure often indicates poor volume control, poor residual renal function and cardiac function, insufficient ultrafiltration and peritoneal permeability, and poor effect of PD model or treatment prescription[19-21]. The control and monitoring of the patient volume and the maintenance of the patient's fluid balance are very important for the patient's technical survival.

According to our previous report, about $86.5 \%$ of the catheter function problems occurred in the first year of PD [22]. In current study, the results showed that transferring to HD due to mechanical problem accounted $16.2 \%$, of which $64.0 \%$ occurred in the first six months. RDPLF study revealed that catheter dysfunction accounted for $18.1 \%$ of the early conversion to HD [5]. In ANZDATA study, mechanical causes accounted for $19.7 \%$ of the early technique failure (including death and transferring to HD) [3]. All these studies have similar results which indicated mechanical problem played an important role in the technique failure due to the transferring to HD during the early stage of PD.

Our previous study demonstrated that early peritonitis was a risk factor for early death-censored technique failure [23]. The current study also demonstrated that peritonitis was not only a cause but also a risk factor associated with technique failure during the first year of PD [24]. ANZDATA reported that the incidence of direct conversion to HD in new PD patients due to peritonitis within the first 12 months was high as $16.4 \%$ [25]. RDPLF study also showed that patients with early peritonitis had a $53 \%$ increased risk of transferring to HD [26]. A South Africa cohort revealed that the risk of technique failure in patients with more than one attack of peritonitis increased by $90 \%$ [27]. In addition, studies have shown that peritonitis was also associated with an increased risk of all-cause death in PD patients[28, 29]. Recent study in our center found that the impact of peritonitis on mortality was more significant in patients with longer PD 
duration [30]. However, there was no direct evidence that peritonitis increased the risk of death in the early stage of PD.

The current study revealed that elderly patients was significantly associated with technique failure, in particularly, the death, but not with transferring to HD in the first year of PD. ANZDATA's study demonstrated that age $>70$ was an independent risk factor for early technique failure (including death) in PD, with a $43 \%$ higher risk compared to younger PD patients [3]. It has been documented that history of $H D$ is a risk factor for technique failure in previous studies $[3,5,12]$. Here we also demonstrated that patients with a previous history of HD had an increased risk of early technique failure. In addition, our study found that PD patients with complete self-care have a lower risk of death during the first year of PD. McGill, et al reported that the risk of death of working patients decreased by $18 \%$, the risk of conversion to $\mathrm{HD}$ decreased by $27 \%$ [31]. Patients with old age, previous history of HD or frailty have the problems that may affect their compliance to PD treatment and therefore affect their prognosis [32]. Attention should be paid for the special population to reduce the technique failure in the early stage of PD.

Both a lower albumin levels and BMI reflect malnutrition. It was well documented that hypoproteinemia was associated with an increased risk of deaths as well as peritonitis [33]. Our previous study demonstrated that patients with serum albumin $<3.5 \mathrm{~g} / \mathrm{dL}$ had a $75 \%$ increased risk of peritonitis[23]. A study from the Middle East found that a dynamic decrease in serum albumin in PD patients indicated an increased risk of transferring to HD [34]. The current results further demonstrated that lower serum albumin was associated with early death and technique failure. ANZDATA's study revealed that lower BMI $\left(<18.5 \mathrm{~kg} / \mathrm{m}^{2}\right)$ increases the risk of early technique failure compared with BMI $\left(18.5-30 \mathrm{~kg} / \mathrm{m}^{2}\right)$ in the firstyear of PD [3]. However, higher BMI in the study of Jaar et al was reported to be associated with the risk of early transferring to $\mathrm{HD}[35]$. Our study showed that low BMI were associated with early technique failure, and that low BMI was significantly associated with death.

We did not find the relationship between diabetes and early technique failure. Previous studies have shown that diabetes significantly increased the risk of technique failure $[13,16]$. ANZDATA have found that diabetes was risk factor for technique failure within one year [3]. Previous studies on patients who withdrew from PD (including death, HD and renal transplantation) within an ultra-early stage (3 months) did not find that diabetes was associated with the drop-out from PD [36]. The effect of education levels on early technique failure was unclear. A study from South Korea reported that patients in junior high school and below were associated with early technique failure [37]. Chidambaram's study found that the level of education in the place of residence is related to the risk of early technique failure [12]. However, we did not demonstrate the effect of education level on early technique failure. In a national study in South Korea, patients who participated in comprehensive health insurance had a relatively low risk of technique failure [17]. In addition, our study revealed that patients with employee medical insurance had a lower risk of death and transfer to HD than patients with resident medical insurance, which is related to the fact that patients with employee health insurance tend to have more stable and higher-paying jobs. Patients who participate in employee medical insurance tend to have a higher proportion and amount of 
reimbursement than resident medical insurance. we think that the type of medical insurance could better represent the social and economic status of patients than their income situation.

Our current investigation has several limitations. First of all, this is a retrospective cohort study that the evidence of causality is not strong. Secondly, due to the large time span of this study, many covariates were not included in the analysis, such as peritoneal function, catheter selection and operation, psychological status, subjective indicators of patients and doctors, and so on. In addition, due to the limitations of the level of economic development, China's APD and icodextrin are still not widely available and therefore are not included in the analysis. Third, factors related to the characteristics of the center are not included in this single-center study, such as PD prescription habits, anti-infective regimen, center size, etc. It is worth noting that we identified the risk factors associated with technique failure during the first year of PD based on demographic and laboratory data, which were not available in previous studies.

In summary, this retrospective cohort study on 2,290 incident PD patients in Southern China revealed incidence of technique failure within the first year of PD was 7.5\%. Advanced age, low BMI, history of congestive heart failure or HD and peritonitis were the factors associated with increased risk, while use employee medical insurance and higher serum albumin associated with decreased risk for the technique failure. Identification of the causes and risk factors may be helpful for the PD center to improve its medical plan and reduce incidence of the technique failure in the early stage of PD. Further studies are needed to clarify the underlying mechanism.

\section{Declarations}

\section{Acknowledgments:}

We thank all nephrologists and nurses in our PD center for their excellent management of PD patients and maintenance of PD database.

\section{Ethical Approval:}

The study was carried out in accord with the ethical principles of the Helsinki Declaration and approved by the Human Ethics Committees of Sun Yat-sen University.

\section{Informed Consent to Participate:}

Written informed consent was obtained from all subjects before the study.

\section{Informed Consent to Publish:}


Written informed consent was obtained from all the patient(s) for their anonymized information to be published in this article.

\section{Trial Registration (where applicable):}

Not application.

\section{Availability of data and materials}

We have put the raw data in the supplementary file.

\section{Consent for publication}

Not applicable

\section{Competing interests}

All authors declare that they have no conflict of interest.

\section{Authorship}

The results presented in this paper have not been published previously in whole or part. The individual contribution of each co-author was as follow: research idea and study design: X.D, H.S.W, H.J.Y, X.Y, X.Q.Y; data acquisition: X.D, H.S.W, R.H.L, C.Y.Y, X.W.D data analysis/interpretation: H.S.W, D.X.W, H.P.M, F.X.H; manuscript writing: X.D, H.S.W, X.Y; supervision or mentorship: X.Y, X.Q.Y.

\section{References}

1. B D, MT K, D G, et al., Contribution of early failure to outcome on peritoneal dialysis. Peritoneal dialysis international: journal of the International Society for Peritoneal Dialysis, 2008. 28(3): p. 25967.DOI.

2. Peng $\mathrm{Y}, \mathrm{Ye} \mathrm{H}, \mathrm{Yi}$ C, et al., Changes in Outcomes over Time Among Incident Peritoneal Dialysis Patients in Southern China. Perit Dial Int, 2019. 39(4): p. 382-389.DOI: 10.3747/pdi.2018.00256.

3. See E J, Johnson D W, Hawley C M, et al., Risk Predictors and Causes of Technique Failure Within the First Year of Peritoneal Dialysis: An Australia and New Zealand Dialysis and Transplant Registry (ANZDATA) Study. Am J Kidney Dis, 2018. 72(2): p. 188-197.DOI: 10.1053/j.ajkd.2017.10.019.

4. Cho Y, See E J, Htay H, et al., Early Peritoneal Dialysis Technique Failure: Review. Perit Dial Int, 2018. 38(5): p. 319-327.DOI: 10.3747/pdi.2018.00017. 
5. Bechade C, Guittet L, Evans D, et al., Early failure in patients starting peritoneal dialysis: a competing risks approach. Nephrol Dial Transplant, 2014. 29(11): p. 2127-35.DOI: 10.1093/ndt/gft055.

6. Li P K, Szeto C C, Piraino B, et al., ISPD Peritonitis Recommendations: 2016 Update on Prevention and Treatment. 2016. 36(5).

7. Delmez J A, Yan G, Bailey J, et al., Cerebrovascular Disease in Maintenance Hemodialysis Patients: Results of the HEMO Study. 2006. 47(1): p. 131-138.DOI.

8. Cheung A K, Sarnak M J, Yan G, et al., Cardiac diseases in maintenance hemodialysis patients: results of the HEMO Study. 2004. 65(6): p. 2380-2389.DOI.

9. Levey A S, Bosch J P, Lewis J B, et al., A more accurate method to estimate glomerular filtration rate from serum creatinine: A new prediction equation. Modification of Diet in Renal Disease Study Group. 1999. 130(6): p. 461-470.DOI.

10. Guo AMujais S, Patient and technique survival on peritoneal dialysis in the United States: evaluation in large incident cohorts. Kidney Int Suppl, 2003(88): p. S3-12.DOI: 10.1046/j.15231755.2003.08801.x.

11. Koniman R, Foo M, Johnson D W, et al., Early technique failure in peritoneal dialysis patients in a multi-ethnic Asian country. International Urology Nephrology, 2020(2).

12. Chidambaram M, Bargman J M, Quinn R R, et al., Patient and physician predictors of peritoneal dialysis technique failure: a population based, retrospective cohort study. Perit Dial Int, 2011. 31(5): p. 565-73.DOI: $10.3747 /$ pdi.2010.00096.

13. Htay H, Cho Y, Pascoe E M, et al., Multicenter Registry Analysis of Center Characteristics Associated with Technique Failure in Patients on Incident Peritoneal Dialysis. Clin J Am Soc Nephrol, 2017. 12(7): p. 1090-1099.DOI: 10.2215/CJN.12321216.

14. Ong L, Ch'ng C, Wee H, et al., Risk of Peritoneal Dialysis-Related Peritonitis in a Multi-Racial Asian Population. 2017. 37(1): p. 35-43.DOI: 10.3747/pdi.2015.00141.

15. Yu X, Yang XHuang N, Management of a rapidly growing peritoneal dialysis population at the First Affiliated Hospital of Sun Yat-sen University. Perit Dial Int, 2014. 34 Suppl 2: p. S31-4.DOI: 10.3747/pdi.2013.00122.

16. Kolesnyk I, Dekker F W, Boeschoten E W, et al., Time-dependent reasons for peritoneal dialysis technique failure and mortality. Perit Dial Int, 2010. 30(2): p. 170-7.DOI: 10.3747/pdi.2008.00277.

17. Lee S, Kim H, Kim K H, et al., Technique failure in Korean incident peritoneal dialysis patients: a national population-based study. Kidney Res Clin Pract, 2016. 35(4): p. 245-251.DOI: 10.1016/j.krcp.2016.08.002.

18. Vrtovsnik F, Verger $C$, Van Biesen W, et al., The impact of volume overload on technique failure in incident peritoneal dialysis patients. Clin Kidney J, 2021. 14(2): p. 570-577.DOI: 10.1093/ckj/sfz175.

19. Tian N, Guo Q, Zhou Q, et al., The Impact of Fluid Overload and Variation on Residual Renal Function in Peritoneal Dialysis Patient. PLoS One, 2016. 11(4): p. e0153115.DOI: 10.1371/journal.pone.0153115. 
20. Trinh EPerl J, The Patient Receiving Automated Peritoneal Dialysis with Volume Overload. Clin J Am Soc Nephrol, 2018. 13(11): p. 1732-1734.DOI: 10.2215/CJN.02570218.

21. Van Biesen W, Verger C, Heaf J, et al., Evolution Over Time of Volume Status and PD-Related Practice Patterns in an Incident Peritoneal Dialysis Cohort. Clin J Am Soc Nephrol, 2019. 14(6): p. 882893.DOI: 10.2215/CJN.11590918.

22. Ye $\mathrm{H}$, Yang $\mathrm{X}, \mathrm{Yi}$ C, et al., Urgent-start peritoneal dialysis for patients with end stage renal disease: a 10-year retrospective study. BMC Nephrol, 2019. 20(1): p. 238.DOI: 10.1186/s12882-019-1408-9.

23. Wu H, Huang R, Yi C, et al., Risk Factors for Early-Onset Peritonitis in Southern Chinese Peritoneal Dialysis Patients. Perit Dial Int, 2016. 36(6): p. 640-646.DOI: 10.3747/pdi.2015.00203.

24. Da Luz L G, Ankawi G, Digvijay K, et al., Technique Failure in Peritoneal Dialysis: Etiologies and Risk Assessment. Blood Purif, 2021. 50(1): p. 42-49.DOI: 10.1159/000508159.

25. See E J, Johnson D W, Hawley C M, et al., EARLY PERITONITIS AND ITS OUTCOME IN INCIDENT PERITONEAL DIALYSIS PATIENTS. Perit Dial Int, 2017: p. pdi.2017.00029.DOI.

26. Lobbedez $T$, Verger $C$, Ryckelynck $J$ P, et al., Is assisted peritoneal dialysis associated with technique survival when competing events are considered? Clin J Am Soc Nephrol, 2012. 7(4): p. 612-8.DOI: 10.2215/CJN.10161011.

27. Isla R A, Mapiye D, Swanepoel C R, et al., Continuous ambulatory peritoneal dialysis in Limpopo province, South Africa: predictors of patient and technique survival. Perit Dial Int, 2014. 34(5): p. 518-25.DOI: $10.3747 /$ pdi.2013.00334.

28. Boudville N, Kemp A, Clayton P, et al., Recent Peritonitis Associates with Mortality among Patients Treated with Peritoneal Dialysis. 2012. 23(8): p. 1398-1405.DOI.

29. Hsieh Y P, Chang C C, Wen Y K, et al., Predictors of Peritonitis and the Impact of Peritonitis on Clinical Outcomes of Continuous Ambulatory Peritoneal Dialysis Patients in Taiwan-10 Years\" Experience in a Single Center. 2014. 34(1): p. 85-94.DOI.

30. Ye H, Zhou Q, Fan L, et al., The impact of peritoneal dialysis-related peritonitis on mortality in peritoneal dialysis patients. BMC Nephrol, 2017. 18(1): p. 186.DOI: 10.1186/s12882-017-0588-4.

31. McGill R L, Weiner D E, Ruthazer R, et al., Transfers to Hemodialysis Among US Patients Initiating Renal Replacement Therapy With Peritoneal Dialysis. Am J Kidney Dis, 2019. 74(5): p. 620-628.DOI: 10.1053/j.ajkd.2019.05.014.

32. Ng J K, Kwan B C, Chow K M, et al., Frailty in Chinese Peritoneal Dialysis Patients: Prevalence and Prognostic Significance. Kidney Blood Press Res, 2016. 41(6): p. 736-745.DOI: 10.1159/000450563.

33. Mehrotra R, Duong U, Jiwakanon S, et al., Serum albumin as a predictor of mortality in peritoneal dialysis: comparisons with hemodialysis. 2011. 58(3): p. 418-28.DOI: 10.1053/j.ajkd.2011.03.018.

34. Khoshhali M, Kazemi I, Hosseini S M, et al., Relationship between trajectories of serum albumin levels and technique failure according to diabetic status in peritoneal dialysis patients: A joint modeling approach. Kidney Res Clin Pract, 2017. 36(2): p. 182-191.DOI: 10.23876/j.krcp.2017.36.2.182. 
35. Jaar B G, Plantinga L C, Crews D C, et al., Timing, causes, predictors and prognosis of switching from peritoneal dialysis to hemodialysis: a prospective study. BMC Nephrol, 2009. 10: p. 3.DOI: 10.1186/1471-2369-10-3.

36. Luo Q, Xia X, Lin Z, et al., Very early withdrawal from treatment in patients starting peritoneal dialysis. Renal Failure, 2018. 40(1): p. 8-14.DOI: 10.1080/0886022x.2017.1419965.

37. Kim H J, Lee J, Park M, et al., Lower Education Level Is a Risk Factor for Peritonitis and Technique Failure but Not a Risk for Overall Mortality in Peritoneal Dialysis under Comprehensive Training System. PLoS One, 2017. 12(1): p. e0169063.DOI: 10.1371/journal.pone.0169063.

\section{Tables}

\section{Table 1}

Baseline Characteristics of Patients Initiated PD in 2006-2015 


\begin{tabular}{|c|c|c|c|c|}
\hline ALL & No Technique Failure & Technique Failure & $\mathbf{P}$ & \\
\hline $\mathrm{N}=2,290$ & $(n=2118)$ & $(n=173)$ & & \\
\hline Male gender & $1,354(59.1 \%)$ & $1,252(59.1 \%)$ & $102(59.0 \%)$ & 0.84 \\
\hline Age & & & & $<0.001$ \\
\hline$<65 Y$ & 1,918(83.8\%) & 1813(85.6\%) & $105(60.7 \%)$ & \\
\hline$\geq 65 Y$ & $372(16.2 \%)$ & $304(14.4 \%)$ & $68(39.3 \%)$ & \\
\hline BMI & & & & $<0.001$ \\
\hline$<18.5 \mathrm{~kg} / \mathrm{m}^{2}$ & $443(19.2 \%)$ & $396(18.6 \%)$ & $47(27.2 \%)$ & \\
\hline $18.5-24 \mathrm{~kg} / \mathrm{m}^{2}$ & $1365(59.0 \%)$ & $1288(60.2 \%)$ & $77(44.5 \%)$ & \\
\hline$>24 \mathrm{~kg} / \mathrm{m}^{2}$ & $482(21.1 \%)$ & $433(20.5 \%)$ & $49(28.3 \%)$ & \\
\hline Education & & & & 0.008 \\
\hline illiterate & $855(37.3 \%)$ & $784(3.7 \%)$ & $71(41.0 \%)$ & \\
\hline primary & $913(39.9 \%)$ & $834(39.4 \%)$ & $79(45.7 \%)$ & \\
\hline higher & $522(22.8 \%)$ & $499(23.6 \%)$ & $23(13.3 \%)$ & \\
\hline Medical insurance & & & & $<0.001$ \\
\hline RMI & $1,355(59.2)$ & $1,222(57.7)$ & 133(76.9) & \\
\hline EMI & $825(36.0)$ & 790(37.3) & $35(20.2)$ & \\
\hline $\mathrm{Cl}$ or FM & $110(4.8)$ & $105(5.0)$ & $5(2.9)$ & \\
\hline Self-care ability & & & & $<0.001$ \\
\hline Not completely & $189(8.25 \%)$ & $153(7.23 \%)$ & $36(20.8 \%)$ & \\
\hline Complete self-care & $2,101(91.6 \%)$ & $1,964(92.8 \%)$ & $137(79.2 \%)$ & \\
\hline Cause of ESKD & & & & $<0.001$ \\
\hline Glomerulonephritis & $1361(59.4 \%)$ & $1283(60.6 \%)$ & $78(45.1 \%)$ & \\
\hline Diabetes & $492(21.5 \%)$ & $435(20.6 \%)$ & $57(33.0 \%)$ & \\
\hline Hypertension & $171(7.5 \%)$ & $159(7.5 \%)$ & $12(6.9 \%)$ & \\
\hline Other & $261(11.6 \%)$ & $240(11.3 \%)$ & $21(15.0 \%)$ & \\
\hline
\end{tabular}

Comorbidity conditions

\begin{tabular}{|lcccr} 
Diabetes & $578(25.2 \%)$ & $512(24.2 \%)$ & $66(38.2 \%)$ & $<0.001$ \\
\hline IHD & $492(21.5 \%)$ & $441(20.8 \%)$ & $51(29.5 \%)$ & $<0.001$
\end{tabular}




\begin{tabular}{|lllll|}
\hline CVD & $539(23.5 \%)$ & $474(22.4 \%)$ & $65(37.6 \%)$ & 0.025 \\
\hline CHF & $70(3.1 \%)$ & $45(2.13 \%)$ & $25(14.5 \%)$ & $<0.001$ \\
\hline Laboratory variables & & & & \\
\hline hemoglobin (g/L) & $79.8 \pm 19.0$ & $79.7 \pm 19.00$ & $82.5 \pm 18.6$ & 0.03 \\
\hline albumin(g/L) & $34.9 \pm 4.89$ & $35.0 \pm 4.86$ & $33.8 \pm 5.06$ & $<0.001$ \\
\hline Scr (mg/dL) & $10.9 \pm 4.35$ & $11.0 \pm 4.38$ & $9.71 \pm 3.81$ & $<0.001$ \\
\hline eGFR (mL/min/1.73 m²) & $5.69 \pm 2.59$ & $5.63 \pm 2.53$ & $6.33 \pm 3.09$ & $<0.001$ \\
\hline calcium (mmol/L) & $1.98 \pm 0.28$ & $1.98 \pm 0.28$ & $1.97 \pm 0.27$ & 0.29 \\
\hline phosphorus(mmol/L) & $2.04 \pm 0.54$ & $1.97 \pm 0.27$ & $1.99 \pm 0.49$ & 0.38 \\
\hline I-PTH (pg/ml) & $412 \pm 307.3$ & $415 \pm 308.4$ & $378 \pm 315.1$ & 0.07 \\
\hline Triglycerides(mmol/L) & $1.55 \pm 0.98$ & $1.54 \pm 0.97$ & $1.74 \pm 1.11$ & $<0.001$ \\
\hline Total cholesterol(mmol/L) & $4.69 \pm 1.39$ & $4.67 \pm 1.36$ & $4.86 \pm 1.67$ & $<0.001$ \\
\hline HDL-C (mmol/L) & $1.03 \pm 0.32$ & $1.04 \pm 0.32$ & $1.01 \pm 0.38$ & 0.21 \\
\hline LDL-C (mmol/L) & $2.84 \pm 1.03$ & $2.84 \pm 1.03$ & $2.88 \pm 1.13$ & 0.78 \\
\hline Duration of RRT & & & & $<0.001$ \\
\hline Nil & $854(37.2 \%)$ & $772(36.6 \%)$ & $80(46.2 \%)$ & \\
\hline$\leq 90 d$ & $1355(59.1 \%)$ & $1273(60.1 \%)$ & $82(47.4 \%)$ & \\
\hline$>90 d$ & $82(3.62 \%)$ & $72(3.40 \%)$ & $11(6.63 \%)$ & \\
\hline Peritonitis & $282(12.3 \%)$ & $240(11.3 \%)$ & $42(24.8 \%)$ & $<0.001$ \\
\hline
\end{tabular}

1.Note: Values are given as number (percentage)

2.Abbreviations: PD: peritoneal dialysis; RMI: Resident medical insurance; EMI:

Employee medical insurance; CI or FM: Commercial insurance or Free medical; I-PTH: immunoreactive parathyroid hormone; Scr: Serum creatinine; HDL-C: high-density lipoprotein cholesterol; LDL-C: low-density lipoprotein cholesterol. GFR: glomerular filtration rate BMI: body mass index; CVD: cardiovascular disease; ESKD: end stage kidney disease; HD: hemodialysis; CHF: congestive heart failure; IHD: ischemic heart disease; PD: peritoneal dialysis; RRT: renal replacement therapy.

\section{Table 2}

Multivariable Competing-Risk Regression Analysis of Technique Failure And Cause-Specific Technique Failure Within First-Year of PD 


\begin{tabular}{|c|c|c|c|c|c|}
\hline $\begin{array}{l}\text { Technique } \\
\text { Failure }\end{array}$ & $\mathrm{D}$ & Death & D & $\begin{array}{l}\text { Transfer } \\
\text { to HD }\end{array}$ & D \\
\hline $\mathrm{HR}(95 \% \mathrm{Cl})$ & & $\mathrm{HR}(95 \% \mathrm{Cl})$ & & $\begin{array}{l}\mathrm{HR}(95 \% \\
\mathrm{Cl})\end{array}$ & \\
\hline $\begin{array}{l}1.06(0.70- \\
1.63)\end{array}$ & 0.76 & $\begin{array}{l}1.13(0.66- \\
1.93)\end{array}$ & 0.65 & $\begin{array}{l}1.05(0.50- \\
2.20)\end{array}$ & 0.90 \\
\hline
\end{tabular}

\section{Age \\ $<65 Y$ \\ $\geq 65 Y$ \\ BMI}

Reference

Reference

reference

2.78(1.82-

4.30)

$<0.001$

4.36(2.46-

7.74)

$<0.001$

1.22(0.53-

0.76

$018.5 \mathrm{~kg} / \mathrm{m} 2$

1.77(1.17-

2.67)

0.01

2.42(1.44-

4.06)

$<0.001$

0.98(0.46-

2.10)

$18.5-24 \mathrm{~kg} / \mathrm{m} 2$

Reference

Reference

reference

$\mathrm{0} 24 \mathrm{~kg} / \mathrm{m} 2$

$1.46(0.98-$

2.14)

0.06

1.38(0.82-

2.35)

0.22

$1.45(0.81-\quad 2.06$

2.60)

\section{Education}

illiterate

Reference

Reference

reference

primary

1.18(0.81-

1.70)

0.39

1.03(0.64-

1.64)

0.91

$0.73(0.38-$

1.40)

0.31

1.28)

0.31

$$
\text { 1.40) }
$$

Medical insurance

RMI

Reference

Reference

Reference

EMI

$0.47(0.32-$

0.69)

Cl or FM

$0.38(0.15-$
$1.01)$

$<0.001$

$0.41(0.24-$

$0.70)$

$<0.001$

$0.55(0.31-$

$0.99)$

$1.43(0.76-\quad 0.26$

2.66)

0.35

$0.78(0.32$

1.91)

0.96

2.06




\begin{tabular}{|c|c|c|c|c|c|c|}
\hline Diabetes & $\begin{array}{l}0.66(0.35- \\
1.27)\end{array}$ & 0.21 & $\begin{array}{l}0.58(0.26- \\
1.30)\end{array}$ & 0.17 & $\begin{array}{l}0.96(0.32- \\
2.89)\end{array}$ & 0.95 \\
\hline Hypertension & $\begin{array}{l}0.80(0.38- \\
1.67)\end{array}$ & 0.54 & $\begin{array}{l}0.70(0.26- \\
1.92)\end{array}$ & 0.49 & $\begin{array}{l}1.01(0.36- \\
2.86)\end{array}$ & 0.97 \\
\hline Other & $\begin{array}{l}1.43(0.88- \\
2.41)\end{array}$ & 0.17 & $\begin{array}{l}1.30(0.64- \\
2.65)\end{array}$ & 0.47 & $\begin{array}{l}1.56(0.75- \\
3.24)\end{array}$ & 0.23 \\
\hline \multicolumn{7}{|c|}{ Comorbidity conditions } \\
\hline Diabetes & $\begin{array}{l}1.52(0.86- \\
2.68)\end{array}$ & 0.15 & $\begin{array}{l}1.93(0.95- \\
3.92)\end{array}$ & 0.07 & $\begin{array}{l}0.97(0.34- \\
2.75)\end{array}$ & 0.99 \\
\hline CVD & $\begin{array}{l}1.57(0.84- \\
2.94)\end{array}$ & 0.16 & $\begin{array}{l}1.72(0.85- \\
3.49)\end{array}$ & 0.13 & $\begin{array}{l}1.37(0.38- \\
4.95)\end{array}$ & 0.63 \\
\hline IHD & $\begin{array}{l}0.67(0.36- \\
1.24)\end{array}$ & \multirow{2}{*}{$\begin{array}{l}0.20 \\
<0.001\end{array}$} & $\begin{array}{l}0.57(0.29- \\
1.08)\end{array}$ & \multirow{2}{*}{$\begin{array}{l}0.09 \\
<0.001\end{array}$} & $\begin{array}{l}1.10(0.28- \\
4.26)\end{array}$ & 0.88 \\
\hline CHF & $\begin{array}{l}2.81(1.58- \\
4.98)\end{array}$ & & $\begin{array}{l}3.52(1.83- \\
6.75)\end{array}$ & & $\begin{array}{l}0.81(0.12- \\
5.40)\end{array}$ & 0.83 \\
\hline
\end{tabular}

\section{Laboratory variables}

\begin{tabular}{|c|c|c|c|c|c|c|}
\hline Hemoglobin(g/L) & $\begin{array}{l}1.01(0.99- \\
1.02)\end{array}$ & 0.17 & $\begin{array}{l}1.01(0.99- \\
1.02)\end{array}$ & 0.15 & $\begin{array}{l}1.00(0.98- \\
1.02)\end{array}$ & 0.93 \\
\hline Albumin(g/L) & $\begin{array}{l}0.93(0.89- \\
0.96)\end{array}$ & $<0.001$ & $\begin{array}{l}0.92(0.88- \\
0.96)\end{array}$ & $<0.001$ & $\begin{array}{l}0.95(0.90- \\
1.00)\end{array}$ & 0.67 \\
\hline $\begin{array}{l}\text { Total } \\
\text { cholesterol (mmol/L) }\end{array}$ & $\begin{array}{l}0.96(0.83- \\
1.12)\end{array}$ & 0.63 & $\begin{array}{l}1.01(0.85- \\
1.19)\end{array}$ & 0.93 & $\begin{array}{l}0.92(0.70- \\
1.21)\end{array}$ & 0.53 \\
\hline Triglycerides (mmol/L) & $\begin{array}{l}0.95(0.85- \\
1.07)\end{array}$ & 0.42 & $\begin{array}{l}1.10(0.88- \\
1.36)\end{array}$ & 0.39 & $\begin{array}{l}0.86(0.70- \\
1.07)\end{array}$ & 0.18 \\
\hline $\operatorname{Scr}(\mathrm{mg} / \mathrm{dL})$ & $\begin{array}{l}0.99(0.91- \\
1.08)\end{array}$ & 0.89 & $\begin{array}{l}0.99(0.89- \\
1.11)\end{array}$ & 0.88 & $\begin{array}{l}1.00(0.89- \\
1.14)\end{array}$ & 0.92 \\
\hline eGFR(mL/min/1.73m²) & $\begin{array}{l}1.02(0.92- \\
1.13)\end{array}$ & 0.76 & $\begin{array}{l}0.98(0.85- \\
1.12)\end{array}$ & 0.77 & $\begin{array}{l}1.09(0.93- \\
1.27)\end{array}$ & 0.33 \\
\hline
\end{tabular}

\section{Duration of RRT}

\begin{tabular}{|c|c|c|c|c|c|c|}
\hline 0 & Reference & & Reference & & reference & \\
\hline$>90$ & $\begin{array}{l}1.20(0.50- \\
2.89)\end{array}$ & 0.68 & $\begin{array}{l}1.36(0.45- \\
4.05)\end{array}$ & 0.59 & $\begin{array}{l}1.07(0.26- \\
4.47)\end{array}$ & 0.92 \\
\hline$\leq 90$ & $\begin{array}{l}1.49(1.05- \\
2.10)\end{array}$ & 0.03 & $\begin{array}{l}1.68(1.05- \\
2.69)\end{array}$ & 0.03 & $\begin{array}{l}1.29(0.75- \\
2.23)\end{array}$ & 0.36 \\
\hline Peritonitis & $\begin{array}{l}2.02(1.36- \\
3.01)\end{array}$ & $<0.001$ & $\begin{array}{l}1.10(0.61- \\
1.94)\end{array}$ & 0.77 & $\begin{array}{l}3.95(2.25- \\
6.80)\end{array}$ & $<0.001$ \\
\hline
\end{tabular}

1. Note: $\mathrm{N}=2,290$

2.transplantation, death and transfer to HD was competing risk respectively. 
3.Abbreviations: PD: peritoneal dialysis; RMI: Resident medical insurance; EMI:

Employee medical insurance; CI or FM: Commercial insurance or Free medical; I-PTH: immunoreactive parathyroid hormone; Scr: Serum creatinine; HDL-C: high-density lipoprotein cholesterol; LDL-C: low-density lipoprotein cholesterol. GFR: glomerular filtration rate BMI: body mass index; CVD: cardiovascular disease; ESKD: end stage kidney disease; HD: hemodialysis; CHF: congestive heart failure; IHD: ischemic heart disease; PD: peritoneal dialysis; RRT: renal replacement therapy.

Table 3

Rates of Technique Failure and Transplantation at the first 6 and 12 Months of PD

\begin{tabular}{lll} 
& 6 month & 12month \\
\hline Technique Failure & $86(3.7 \%)$ & $173(7.5 \%)$ \\
\hline Transfer to HD & $31(36 \%)$ & $65(37 \%)$ \\
\hline Transfer to HD caused by Infection & $8(9 \%)$ & $22(12 \%)$ \\
\hline Transfer to HD caused by Mechanical & $18(21 \%)$ & $28(16 \%)$ \\
\hline Transfer to HD caused by Other & $5(5 \%)$ & $15(8 \%)$ \\
\hline Death & $55(63 \%)$ & $108(62 \%)$ \\
\hline Transplantation & $90(3 \%)$ & $169(7 \%)$ \\
\hline
\end{tabular}

Abbreviations: HD, hemodialysis.

\section{Figures}


(2006.1.1-2015.12.31) all peritoneal dialysis patients followed up in our hospital $(\mathrm{N}=2317)$

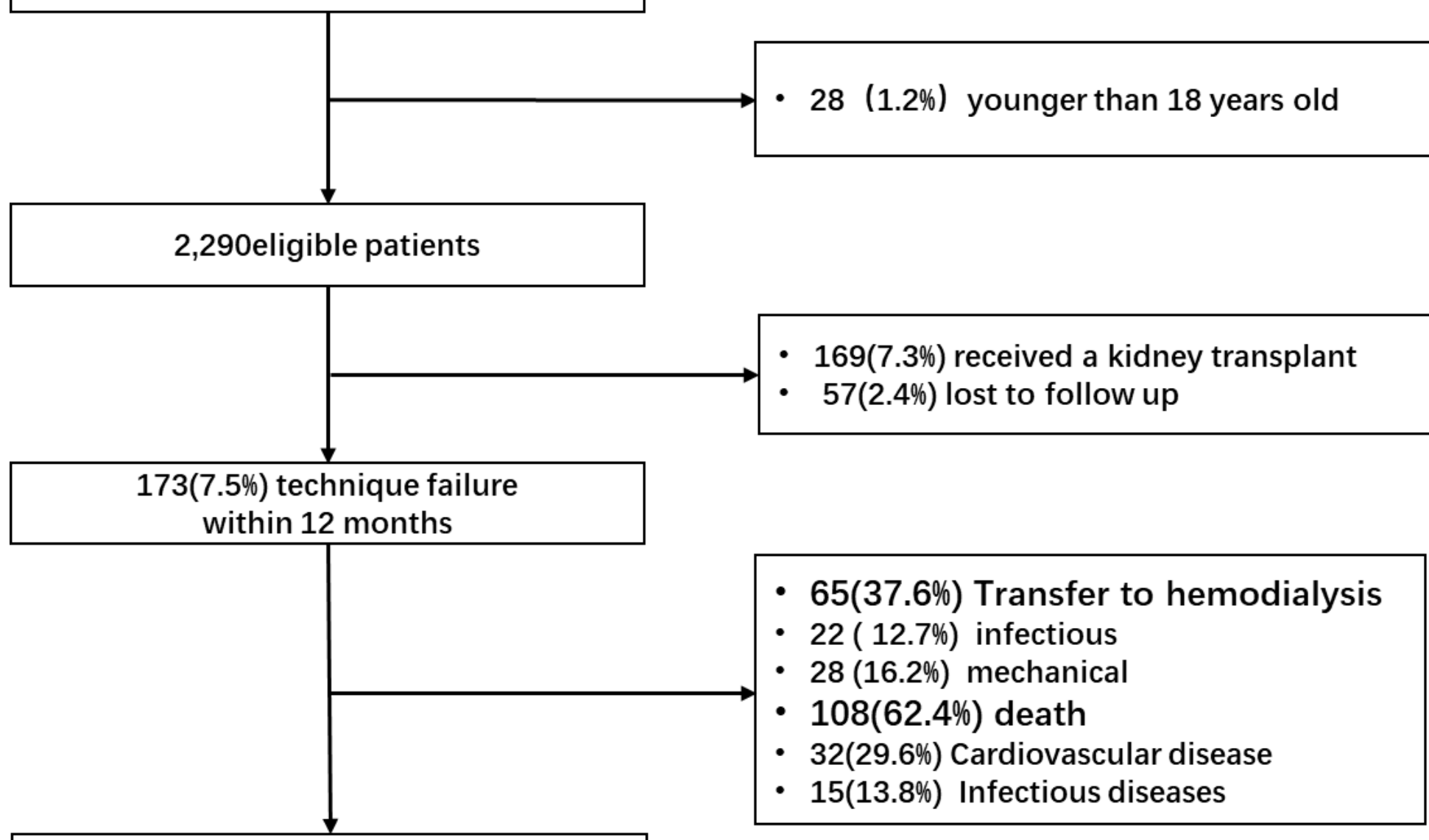

1891(82.6\%)Still peritoneal dialysis at the end of the study

Figure 1

Flow chart of participant selection for this cohort study.

Figure 2

Cumulative incidence of cause-specific technique failure. Curves represent the cumulative incidence of each cause of technique failure, with other causes (death, infectious, mechanical, or other) and transplantation examined as competing risks.

\section{Supplementary Files}

This is a list of supplementary files associated with this preprint. Click to download. 
- RAWDATA20211230.csv

Page 20/20 